\title{
Recent Advances in the Treatment and Prophylaxis of Leprosy.
}

\author{
Cameron Lecture by Sir Leonard Rogers.
}

The full abstract of this Lecture delivered at Edinburgh University appeared in the "British Medical Fournal," November 23rd, 1929. We are indebted to the Editor of the "British Medical Fournal " for permission to reprint it.

OIR LEONARD ROGERS stated that the time was ripe $\checkmark$ for a review of the recent advances in the treament of leprosy and their bearing on prophylactic measures to reduce the incidence of this ancient and dreaded disease. It was estimated that it affected some three million people in the world, and about half a million in the British Empire. The task of reducing leprosy was heavy. It would never be accomplished by the mediæval method of compulsory segregation, with the inevitable hiding of patients in the early more curable stages of the disease. Sir I,eonard pointed out that after a close study of the literature of the subject he had come to the conclusion that in 80 per cent. of the cases the infection was contracted by living in the same house with a leper, although only 3 to 5 per cent. of those so exposed contracted the disease; this showed that the disease was only slightly contagious. In 80 per cent. the incubation period was less than five years.

\section{Evolution of Leprosy Therapy.}

Among the more common and unsatisfactory methods of treating leprosy formerly might be mentioned local applications and surgical operations; the use of mercurial, copper, gold, arsenical, and antimony compounds ; vaccines made from supposed cultures of the lepra bacillus and other saprophytic organisms, including nastin; tuberculin; sterile emulsions of leprotic nodules; and protein shock treatment. Of all of these it might be said that in no appreciable percentage of cases had they brought about lasting disappearance of all the active signs of leprosy. The fallacies of treatment were next pointed out, including those due to the variable course of the disease, and especially the spontaneous great improvement which temporarily followed the acute phase, and was likely to be erroneously attributed to any drug which happened to be given at that time. It was 
necessary to treat a considerable number of cases for long periods to enable any reliable conclusions to be reached.

The one ray of hope derived from a study of the older literature was the frequency with which slight febrile and local reactions, more particularly after vaccines, had of ten been followed by considerable temporary improvement. If a method could be devised of producing repeated slight reactions with a fair degree of cetainty an advance should result. Potassium iodide had long been known to cause reactions of diagnostic value, and recently E. Muir reported good results from this drug in doses of from 1 to 240 grains.

The story was then related of how the old Indian remedy chaulmoogra oil was introduced to European medicine by Mouart of the Indian Medical Service in 1854, and its failure to do more than retard the progress of typical cases of leprosy, owing to its nauseating nature. In 1904-7 Power had separated chaulmoogric and hydnocarpic acids from both the chaulmoogra oil of Burma and the hydnocarpus oils of India and Indo-China. In 1914, Victor G. Heiser recorded promising results from prolonged and painful intramuscular injections of the Mercado mixture containing one-third of chaulmoogra oil ; in the following year Sir Leonard Rogers, at Heiser's request, renewed his former efforts to obtain a soluble preparation of the active principle of the oils on the lines of his previous success with emetine, the active principle of ipecacuanha. He soon found that a solution of sodium gynocardate injected subcutaneously, although painful, was an advance on the oral treatment. In 1916, he discovered that this preparation could also be used intravenously with safety; slight febrile or local reactions occurred, accompanied by extensive breaking up of the bacilli in the leprous tissues, and followed by more rapid improvement and the ultimate disappearance of all clinical signs and bacterial infection in a number of comparatively early cases obtained from among hospital outpatients. Further repeated injections of this preparation produced gradual breaking up and disappearance of the lepra bacilli in nodules, and the slow development of immunity even when little or no evident reaction occurred, with eventual clinical cure and removal of all infectivity. As the result of several years' patient work it was established that the high melting point chaulmoogric acid fraction was useless, but the lower melting point hydnocarpic acid and the so-called gynocardic acid constituted the active rts of the oils, which could best be obtained from the eed of the hydnocarpus wightiana of Southern India. 
Of 51 cases of leprosy treated with the hydnocarpates and gynocardates for three months and upwards in the course of five years, 40 per cent. completely cleared up, and another 40 per cent. were greatly improved.

Meanwhile, in 1919, a useful modification of Sir Leonard Rogers' method had been introduced by Hollman and Dean in Honolulu-namely the less troublesome intramuscular injections of the ethyl esters of the whole oil in the form of a thin oily liquid; this preparation had for long been used with much success in Hawaii, at the Culion leper settlement of the Philippines, and by E. Muir in Calcutta. In 1925, E. Muir reported success following the subcutaneous and intramuscular injection of pure fresh hydnocarpus wightiana oil with 4 per cent. creosote as an antiseptic, which was less than one-twentieth the cost of a good ethyl ester. In 1927, the lecturer recorded the elimination of the vein difficulty by using sodium hydnocarpate. Dr. T. A. Henry prepared a substance-alepolthe sodium salt of the lower melting point fatty acids of hydnocarpus wightiana oil, from which he had removed the irritant properties of Rogers' early preparations. Alepol was very effective and painless, whether injected subcutaneously or intramuscularly ; it could also be used intravenously in the few cases requiring this procedure by Muir's simple expedient of drawing up about an equal quantity of blood from the vein into the syringe which contained the dose, and then injecting the mixture.

The results obtained in the largest series of cases yet reported showed 41 per cent. of clinical cures by Rogers' intravenous method, and 31 per cent. by Muir's subcutaneous and intramuscular injections, both series being mainly composed of earlier hospital cases than those seen in leper asylums under the compulsory system. Dr. Isabel Kerr, in her leper hospital at Dichpali, obtained 17 per cent. to 19 per cent. cleared up, and 63 per cent. became bacteriologically negative and uninfective. The most extensive trial in 6,000 advanced cases of eight years' average duration on admission at Culion, reported on by $H$. W. Wade and C. B. Lara, showed from 15 per cent. clinical cures, with a total now amounting to over 1,000 cases. Thus it was clear that, as might have been expected, the results were much better in the case of persons in the early stages who had been attracted to voluntary clinics than in the patients with advanced disease, who were obtained by compulsory segregatation. The importance of finding the early stages was well illustrated by the results in 486 lepers treated at the Honolulu hospital during five years; these showed 8 per cent. 
of recoveries in very advanced cases, 38 per cent. in moderately advanced and 64 per cent. in early cases. It was clear, therefore, that anything which led patients in the early curable stages to hide away, as was inevitable under rigid compulsory segregation, might in these days easily do more harm than good, and actually retard the reduction of leprosy.

Sir Leonard Rogers then discussed the necessity of modifying rigid compulsory segregation in order to attract the early clinically curable cases. He advocated the system already adopted in Mauritius, and about to be legalised in British Guiana, namely, that cases reported by an expert committee to be non infectious should be treated at clinics or at home. No such compulsion was attempted in our tropical African possessions, yet some 5,000 new cases were attracted to voluntary clinics and colonies last year alone. In view of the facts already mentioned-that 80 per cent. of leprosy was contracted by living in the same house as a leper, and that in 80 per cent. the incubation period was under five years - the lecturer submitted a scheme which provided that as soon as a leper was found all his household were examined for early cases; this was repeated every six months for five years. In this way, some 80 per cent. of the probable infections from the case should be detected in the early stage; a considerable majority of the patients would be cured and prevented from becoming infective, with a corresponding reduction in the remaining foci of infection. Since patients with advanced nodular disease died in from eight to ten years, and the nerve cases became uninfective, by repeating this process for a second five years few infective cases would remain. A great reduction of leprosy would result within a single decade wherever this simple plan could be put into operation. The recent advances in the treatment of leprosy should therefore be regarded as being by no means the least of the romances of modern medicine. 